\title{
A bioliteracia e a cidadania: os alunos do ensino secundário
}

\author{
Conceição Soeiro
}

\begin{abstract}
Resumo
A Escola não pode ignorar a multiplicidade de problemas deste mundo globalizado, cabendo-lhe um papel acrescido de responsabilidade na promoção da bioliteracia dos jovens. Neste século, as grandes descobertas no campo da Biologia têm confrontado os cidadãos com questões que, pela sua natureza, exigem destes um grau de bioliteracia que os capacite a intervir e agir na sociedade. Neste artigo, vamos apresentar os dados resultantes de um trabalho de investigação centrado na avaliação do grau de bioliteracia dos alunos do ensino secundário, nos anos de 2008-2009 e 2009-2010, cuja reforma vigente fora promulgada pelo XV Governo Constitucional, em 2004. A opção metodológica teve como base a aplicação de um questionário aos alunos do ensino secundário. Os resultados obtidos permitiram constatar diferenças significativas no nível geral de bioliteracia dos estudantes do ensino secundário consoante determinadas condições sociodemográficas. De um modo geral, podemos concluir, pelos resultados obtidos, que metodologias ativas, que vão ao encontro das principais premissas nas atuais políticas educativas, podem ter contribuído para os resultados globalmente satisfatórios na bioliteracia dos alunos em fase de conclusão do ensino secundário.
\end{abstract}

Palavras-chave:

bioliteracia; ensino secundário; ensino da Biologia; políticas educativas. 


\section{The bioliteracia and citizenship: the secondary school students}

Abstract: The School cannot ignore the multiplicity of problems of this globalized world, and it has an added role of being responsible for promoting bioliteracy in young people. This century's major discoveries in the field of Biology have confronted citizens with issues which, by their nature, require a level of bioliteracy that enables them to intervene and act in society. In this paper, research work was conducted on the evaluation of the degree of bioliteracy in secondary school students in the 2008-2009 and 2009-2010 academic years, whose in force reformation had been promulgated by the 15th Constitutional Government in 2004. In this study, a questionnaire was applied to secondary school students The results obtained have allowed us to observe significant differences as regards the bioliteracy of secondary school students depending on specific socio-demographic conditions. Generally speaking, we can conclude from the results obtained that active methodologies, which meet the main premises in present day educational policies, may have contributed to the globally satisfactory results of bioliteracy of students in the final stage of their secondary education.

Keywords: bioliteracia; secondary education; teaching of biology; education policies.

\section{La Bioliteracy et la citoyenneté: les élèves du secondaire}

Résumé: L'école ne peut pas ignorer la multiplicité de problèmes dans ce monde globalisé, avec un rôle accru des responsabilités dans la promotion de la bioliteracy des jeunes. Dans ce siècle, les grandes découvertes dans le domaine de la biologie ont confronté les citoyens avec des questions qui, par leur nature, nécessitent d'un certain degré de bioliteracy qui leur permette d'intervenir et d'agir dans la société. Dans cet article, nous présentons les données d'un travail de recherche axé sur l'évaluation du degré de bioliteracy des élèves du secondaire dans les années 2008-2009 et 2009-2010, dont la courant réforme courante a été promulguée par le XV Gouvernement Constitutionnel en 2004. L'option méthodologique est centrée sur l'application d'un questionnaire aux élèves du secondaire. Les résultats obtenus ont permis de constater des différences significatives dans le niveau général de bioliteracy des lycéens selon certaines conditions socio-démographiques. En général, nous pouvons conclure à travers les résultats obtenus que les méthodes actives, qui sont défendues dans les actuelles politiques éducatives, peuvent avoir contribué aux résultats globalement satisfaisants dans bioliteracy des étudiants en phase d'achèvement du secondaire.

Mots clés: bioliteracy; enseignement secondaire; enseignement de la Biologie; politiques éducatives

\section{El bioliteracia y la ciudadanía: los estudiantes de la escuela secundaria}

Resumen:La escuela no puede ignorar la multiplicidad de problemas en este mundo globalizado, con un papel más importante de la responsabilidad en la promoción de la juventud bioliteracia. En este siglo, los grandes descubrimientos en el campo de la biología han confrontado a los ciudadanos con temas que por su naturaleza, requieren un grado de bioliteracia que les permite intervenir y actuar en la sociedad. En este artículo se presentan los datos resultantes de un trabajo de investigación que se centró en la evaluación del grado de bioliteracia de estudiantes de secundaria en los años 2008-2009 y 2009-2010, cuya corriente reforma promulgada por el gobierno constitucional de XV en 2004. La opción metodológica se basó en la aplicación de un cuestionario a los estudiantes de educación secundaria. Los resultados obtenidos permitieron observar diferencias significativas en el nivel General de bioliteracia de los estudiantes de escuela secundaria según ciertas condiciones socio-demográficas. En general, podemos concluir los resultados obtenidos que metodologías activas, que se reunirán los principales supuestos en las políticas educativas actuales, pueden haber contribuido a los resultados en general satisfactorios en bioliteracia de estudiantes en fase de finalización de escuela secundaria.

Palabras clave: bioliteracia; educación secundaria; enseñanza de la Biología; políticas educativas. 


\section{Introdução}

A ciência e a tecnologia estão presentes em todos os setores da vida contemporânea e estão provocando profundas transformações económicas, sociais e culturais. Neste contexto, a Biologia tem vindo a ocupar uma posição relevante, especialmente nas áreas da Biologia Molecular e Genética, áreas científicas que passaram a ser discutidas na Escola e na Sociedade 1 .

Como refere Hodson (2008), é impraticável pensar na literacia científica como disciplina absoluta, pois sempre dependerá do contexto em que está sendo desenvolvida, dos objetivos propostos, da possibilidade de aplicação, da sociedade em que se insere. Do mesmo modo, à medida que a própria ciência se transforma ou progride, também a nossa perspetiva do que conta como literacia científica legítima muda.

Num âmbito mais restrito da literacia científica, a bioliteracia desempenha um papel importante na compreensão de muitos fenómenos biológicos e de problemas sociais, contribuindo para a formação de cidadãos capazes de analisar e elaborar pareceres sustentados e agir se necessário for, tal como se pode entender da leitura dos programas curriculares do ensino secundário. Este trabalho científico focaliza-se essencialmente no período decorrido entre 2004 e 2009, na medida em que a investigação empírica ocorreu no ano letivo de 2008-2009, quando estava em vigor a reforma promulgada pelo XV Governo Constitucional. A questão de investigação que norteou este trabalho foi a seguinte: Qual a compreensão em bioliteracia dos alunos do ensino secundário na área de ciências e em que medida esta corresponde aos objetivos fixados no discurso político e nos normativos legais? Os objectivos que presidiram a esta investigação foram os seguintes: (i) Avaliar os níveis de compreensão conceptual em bioliteracia de um grupo de alunos finalistas do ensino secundário no âmbito da reforma de 2004; (ii) Identificar conteúdos programáticos da disciplina de Biologia e o seu contributo para a bioliteracia.

\section{Enquadramento}

Nos tempos atuais, os avanços obtidos na área da biologia têm um impacto direto ou indireto em variadíssimas atividades económicas e em novos mercados.

De acordo com Cruz (2008, p.11), a "sustentabilidade do Homem no Planeta depende da forma como usar os recursos endógenos e renováveis. Daqui, a necessidade de estabelecer políticas públicas para a preservação da sustentabilidade global, o combate às alterações climáticas, de estímulo ao uso racional da energia e de redução dos combustíveis fósseis".

Há hoje uma preocupação generalizada, a nível mundial, com o melhoramento da literacia científica ${ }^{2}$ uma vez que ela interfere na formação de especialistas e cientistas cujo 
contributo será, em parte, responsável por um melhor desenvolvimento económico, social, científico, cultural e cívico, em suma, uma sociedade mais justa e democrática.

As ciências biológicas têm vindo a ocupar uma posição relevante que já the valeu o epíteto de Ciência do século XXI. A torrente de informações advindas das recentes descobertas científicas, principalmente nas áreas da biologia molecular e genética, tem-se expandido progressivamente do meio académico ao espaço público, por meio de revistas especializadas e dos mass-media.

Como nos recorda Pearson (2009, p.722), remetendo para a definição dada pela organização costa-riquenha InBio, a bioliteracia comporta manifestações comportamentais: "[it] leads the individual to comprehend biodiversity, to adopt an ethic of respecting nature, and to assume their responsability for the management and conservation of all life forms". A ênfase dada à bioliteracia, nos nossos dias, ocorre de mudanças económicas, sociais e culturais resultantes de descobertas científicas e tecnológicas no âmbito das ciências biológicas. Neste sentido, os decisores políticos e os especialistas por eles escolhidos devem prestar cada vez mais atenção aos conteúdos da disciplina de Biologia tendo em vista melhorar as competências dos estudantes: "This demands more attention to teaching children how to learn, manage their own learning, analyse problems, as well as design and implement solutions" (Griffiths, 2003, prefácio).

Segundo Audigier (2000, citado in Afonso, 2004), no que respeita à educação para a cidadania, os jovens devem possuir um conjunto de competências de âmbito ético, social, cultural e económico. Ou seja, é importante para os alunos:

Conhecer os temas fundamentais da cidadania, (...) Estar informado e ter capacidade de pronunciar-se sobre as questões e problemas do mundo atual, (...) Ter capacidade de refletir sobre a sua ação e a dos outros, de forma consciente, justa e responsável. (...) Ter capacidade de escuta, reflexão, sentido crítico, curiosidade, imaginação, questionamento, debate e decisão. (pp. 455-456)

\section{Opção metodológica}

Com o objetivo de analisar o nível de bioliteracia em estudantes do ensino secundário a nível nacional, optou-se por conduzir um estudo quantitativo com recurso a um questionário aplicado a estudantes no ensino secundário para avaliação de conhecimentos ao nível da Biologia. O questionário foi enviado para todas as escolas que possuíam na sua oferta formativa a disciplina de Biologia, inserida no curso de Ciências e Tecnologias. 
Este estudo foi desenvolvido numa abordagem quantitativa, suportado em estatísticas descritivas e inferenciais aos dados recolhidos de uma amostra com carácter aleatório a nível nacional dos jovens do $12^{\circ}$ ano agrupamento de Ciências.

A população alvo para este estudo foi constituída por um total de 606 questionários respondidos por 234 alunos do sexo masculino (38,6\%) e 372 do sexo feminino $(61,4 \%)$, cujas idades não diferem de forma significativa, situando-se na faixa etária dos cerca de 17 anos e meio.

A grande maioria dos respondentes $(465=79,3 \%)$ frequentava escolas localizadas na região de Lisboa e Vale do Tejo; 38 (6,5\%) na região do Algarve; 32 (5,5\%) no Norte; 31 (5,3\%) no Centro; e apenas 20 (3,4\%) na região do Alentejo. Contudo, do total de 606 inquiridos, 20 não responderam à questão relativa à cidade de residência. $A$ análise entre as diversas regiões do país demonstrou diferentes execuções consoante a proveniência, mostrando uma média de execução superior na região do Algarve e na de Lisboa e Vale do Tejo. A maior parte dos inquiridos afirma que irá prosseguir os estudos a nível do ensino superior $(94,9 \%)$ e mais de metade deles declara pretender ingressar em cursos relacionados com as Ciências da Vida (64,2\%). Uma proporção superior de raparigas escolheu os cursos de Ciências da Vida, enquanto a preferência dos rapazes está centrada sobretudo nas áreas científicas e tecnológicas, como por exemplo, as Engenharias, a Informática ou a Matemática. Só um pequeno número de inquiridos declarou não possuir a nacionalidade portuguesa, correspondente a 5,9\% de toda a amostra. A quase totalidade vivia com a família $(99,3 \%)$ e o seu agregado era constituído, na maior parte dos casos, entre três e quatro elementos $(70,5 \%)$.

Do ponto de vista socioeconómico, o rendimento mensal global situava-se entre 1.000 e 2.000 euros para 38,7\% das famílias dos respondentes e entre 2.000 e 4.000 euros para $26,2 \%$. Nas faixas mais baixas, o rendimento oscilava entre 500 e 1.000 euros (16,7\%), sendo inferior a 500 euros para 4,0\% das famílias. Enquanto nos níveis superiores, com rendimento entre 4.000 e 10.000 euros situavam-se 10,6\% e com mais de 10.000 euros, 3,8\% das famílias. Foi igualmente verificado um efeito de associação estatisticamente significativo entre sexo e a variável rendimento mensal global do agregado familiar. Este resultado permitiu demonstrar uma percentagem superior de alunas na categoria de rendimento do agregado entre 1.000 e 2.000 euros (40,5\%) e entre 500 e 1.000 ou inferior a 500 euros (26,6\%). Em percentagem aproximada estão aquelas cujo rendimento familiar se situa entre os 2.000 e 4.000 euros (24,1\%); com mais de 4.000 euros apenas estão $8,9 \%$ das respondentes. Em contrapartida, o rendimento do agregado familiar dos rapazes distribuía-se de forma diferente: entre 1.000 e 2.000 euros estavam 35,8\%, mas entre 2.000 e 4.000 euros contavam-se $29,4 \%$. Com mais de 4.000 euros eram cerca de $17,9 \%$ e, no valor oposto, com menos de 1.000 euros situavam-se 14,1\%.

O grau de escolaridade dos pais mais frequente na amostra é o $3 .^{\circ}$ ciclo do ensino básico (25,7\% para os pais e 31,1\% para as mães), seguido do grau de Licenciatura com 
24,4\% e 23,9\%, respetivamente. Com menores habilitações ( $1 .{ }^{\circ}$ ciclo do ensino básico), encontravam-se $12,5 \%$ de pais e $8,4 \%$ de mães. Com habilitações mais elevadas, ou seja, os graus de Mestrado e Doutoramento, possuíam-nos cerca de 10,3\% de pais e 10,2\% de mães.

Relativamente às profissões dos pais dos inquiridos, os dados foram reunidos em dez grupos diferentes, de acordo com a Classificação Nacional de Profissões (CNP). Os pais foram classificados maioritariamente como especialistas das profissões intelectuais e científicas (22,4\%) ou técnicos profissionais de nível intermédio (20,9\%), enquanto 21,7\% das mães pertenciam a profissões intelectuais e científicas e pessoal administrativo (19,3\%). No entanto, na distribuição das profissões de ambos os elementos familiares, não se registam diferenças muito significativas.

Finalmente, a tabela escolhida para análise das respostas baseou-se na avaliação quantitativa, expressa em percentagens de 0 a 100, à qual corresponde uma apreciação qualitativa, conforme a seguinte escala: 'Muito insatisfatório' com um intervalo percentual de correspondência de [0-24]; 'Insatisfatório' correspondente a [25 -49]; 'Satisfatório' para [50-66,7]; 'Bom' para [66,8-83,3]; e 'Muito Bom' para [83,4-100]. Neste sentido, foram criados três indicadores de desempenho nesta prova, nomeadamente, a Cotação Total, Grau de Confiança Total e Cotação Total Ponderada, que serão descritos adiante nos pontos relativos à análise de inferência de cada um destes indicadores.

Na realidade, a educação formal continua a ser o veículo privilegiado que melhor contribui para a construção do saber, neste caso concreto, as Ciências da Vida. Quando os alunos foram inquiridos sobre a fonte do conhecimento que thes permitiu responder ao questionário ${ }^{3}$, 75,6\% indicam como mais importante as aulas. Estas respostas vêm salientar o papel dos professores no processo de ensino-aprendizagem. Só um pequeno grupo dos inquiridos considerou que foi na Escola, mas não em ambiente de aulas, que adquiriu um número mais significativo de conhecimentos (5,4\%), o que reflete que os espaços escolares não são devidamente organizados para potenciar maior eficácia do processo de ensino-aprendizagem nem tão-pouco como outros lugares de partilha de conhecimentos entre pares. Além disso, face a estes resultados, as atividades extracurriculares parecem não ter especial relevância.

A internet, meio privilegiado dos jovens para ocupação dos seus tempos livres, apenas é indicada por uma média de 5,3\% de alunos, registando-se, porém, uma acentuada diferença entre os sexos, respondendo $8,5 \%$ de rapazes e $3,2 \%$ de raparigas. Do mesmo modo, a Televisão e outros meios audiovisuais deram um contributo mínimo para a aquisição dos conhecimentos em causa (3,3\%).

Quanto à Televisão, sabemos que o seu papel é fundamentalmente lúdico, apesar de haver alguns programas de divulgação (por exemplo, os Discovery Channel, Discovery Science e National Geographic), e debates de caráter informativo, que despertam interes- 
se nos jovens e podem contribuir para o melhoramento da sua bioliteracia, embora isso não seja valorizado por eles.

Também a Família parece ter um papel pouco relevante, 2,8\%, embora a maior parte dos inquiridos tenha informado que os seus progenitores possuíam como habilitação académica o $3 .^{\circ}$ ciclo do ensino básico.

\section{Aprentação e discussão dos resultados}

$\mathrm{Na}$ análise dos temas selecionados, o enfoque principal incide na relação que existe entre a bioliteracia adquirida durante os estudos secundários e a capacitação dos alunos para compreender os grandes desafios da sociedade. Por esta razão, a ordem das questões formuladas não é aqui seguida.

No respeitante às questões sobre Ecologia, área científica contemplada no programa de Biologia e Geologia do ensino secundário, o questionário indagava sobre o esgotamento dos recursos energéticos não renováveis. A percentagem de respostas que o julgam "extremamente grave" é de 51,8\%, equivalente ao grau qualitativo "satisfatório". No entanto, um número muito razoável de alunos respondeu considerar esse esgotamento um problema "muito grave" (30,4\%). Se juntar este valor ao anterior, podemos concluir que o tema não é alheio aos inquiridos, independentemente do sexo.

A outra questão pretendia avaliar os efeitos da aplicação do Protocolo de Quioto relativo às alterações climáticas e que foi objeto de larga discussão na Assembleia da República ${ }^{4}$. Constando de cinco alíneas de resposta, a média dos que acertaram é de 62,3\% e insere-se no grau "Satisfatório", não encontrando diferenças significativas entre os dois sexos Numa primeira leitura, posso afirmar que aquele valor percentual revela uma perceção e identificação por parte dos respondentes dos problemas ambientais e da necessidade de aplicação de políticas públicas eficazes que reparem os danos causados por atuações irracionais e insensatas que, visando apenas a lei do lucro imediato, põem em perigo a sustentabilidade da vida humana na Terra.

No entanto, encontrou-se desconhecimento relativamente a alguns dos pressupostos do Protocolo; no conjunto das cinco alíneas apresentadas, uma média de 7,3\% dos inquiridos não respondeu. Se uma grande maioria dos alunos identifica alguns dos aspetos benéficos contidos no documento - a redução da emissão dos gases que provocam o efeito de estufa (89,1\%), a promoção do uso de fontes energéticas renováveis (83,7\%) -, não são muitos aqueles que relacionam os efeitos benéficos decorrentes da aplicação do Protocolo - a manutenção da biodiversidade (39,6\%), a reforma dos setores de energia e transportes (43,4\%). Além disso, constatamos que só cerca de metade dos respondentes identifica o princípio que contempla a proteção das florestas e outras identidades biológicas fixadoras de carbono $(56,1 \%)$. 
Atendendo a que a genética molecular desempenha hoje, um papel relevante na resolução de muitos problemas de saúde e de bem-estar, e na medicina forense, elaboramos sete questões destinadas a avaliar o grau de conhecimento dos inquiridos relativamente a uma temática tão promissora quanto inquietante e, do mesmo modo, alvo do debate político. Daí, o facto de serem abordadas no início do questionário.

A primeira questão incide na relação entre genes, ADN e cromossomas e pretende diagnosticar as conceções que os alunos possuem sobre estes termos e respetivos conceitos, ferramentas básicas da biologia molecular, e como se encontra armazenada nas células a informação genética.

Dos inquiridos, 84\% responderam acertadamente, ou seja, "os genes são compostos de ADN e situam-se no interior de cromossomas", E não se registam diferenças significativas entre os alunos respondentes (82,5\%) e as alunas (84,7\%).

Este resultado significativo, equivalente a "Muito Bom", poderá ser explicado pela continuidade temporal e crescente aprofundamento contemplados nos programas de $10{ }^{\circ}$,


atitudes críticas e ativas dos alunos.

$\mathrm{Na}$ questão que se destina à identificação da constituição química e estrutural do modelo de ADN, responderam corretamente $91,4 \%$ dos inquiridos, ou seja, o equivalente a "Muito Bom" da escala qualitativa. Se tivermos em atenção o sexo, verificamos que praticamente o total das raparigas respondeu acertadamente $(92,5 \%)$ enquanto os rapazes apresentam um desempenho ligeiramente menor (89,7\%).

A questão que incide nas condições de emparelhamento do $\mathrm{ARNt}^{5} \mathrm{com}$ o $\mathrm{ARNm}$, tendo como objetivo avaliar o conhecimento dos alunos relativamente ao fluxo de informação no interior da célula e da conversão da linguagem do ADN para a linguagem das proteínas. Para os alunos reveste-se de grande interesse a compreensão do dogma central da biologia molecular, segundo o qual a sequenciação de determinado ADN leva ao conhecimento de todas as proteínas que podem ser sintetizadas a partir dele.

A análise dos proteomas (conjunto de proteínas que advém da expressão dos genes) tem hoje uma aplicação em áreas como a medicina, a agricultura e a pecuária. Por outro lado, já estão decifrados genomas de um grande número de espécies incluindo a humana, cujas aplicações incidem no diagnóstico precoce de doenças de predisposição genética, na produção de compostos específicos para o seu tratamento e, ainda, na determinação da identidade individual (ADN forense).

Face à importância referida, seria expectável que os alunos inquiridos demonstrassem maior domínio da temática. No entanto, menos da metade responderam acertadamente $(45,4 \%)$, quer os rapazes quer as raparigas.

Em função dos resultados, poder-se-á considerar que o mecanismo da síntese proteica (conducente ao conhecimento da informação contida nos genes estruturais) para $54,6 \%$ dos alunos não ultrapassou o patamar da memorização com uma retenção tem- 
poral pouco duradoura, não revelando uma compreensão do esquema conceptual. Para este desconhecimento, além das possíveis causas de natureza pedagógica, não podemos esquecer o interesse individual e coletivo relativamente às temáticas, o gosto pelo conhecimento, numa sociedade cheia de solicitações que não exigem esforço.

Em outra questão, pretendemos avaliar o grau de conhecimento do conceito de gene estrutural. Foram apenas 9,9\% as respostas corretas. É de registar que os alunos revelam, apesar de tudo, um conhecimento ligeiramente superior relativamente às raparigas, ainda que muito insatisfatório.

O percentual correto obtido nestas respostas fica muito aquém do desejável uma vez que a temática em que esta questão está incluída tem aplicações tão relevantes para a sociedade, como acima já referimos.

A questão em que se procura saber se o aluno identifica as fases implicadas na conversão da informação codificada no ADN para a linguagem das proteínas, ou seja, um conhecimento importante para a identificação de muitas doenças a partir das anomalias detetadas nas proteínas. Foram registadas 53,8\% de respostas certas não havendo discrepâncias significativas em função do sexo.

As respostas obtidas refletem que uma parte dos alunos tem dificuldade em atingir alguns dos patamares da atividade cognitiva, o que pode, em parte, explicar o grau de desinteresse por estas matérias.

Fazendo uma análise globalizante das três questões relacionadas com a síntese proteica, ressalta que os vários níveis de informação e grau de conhecimento foram mais memorizados do que compreendidos, seguindo uma escala decrescente, que parte do geral para o particular, do genérico para o específico.

A questão que se ocupa de uma das propriedades do ADN - a replicação - que permite a manutenção da informação genética, tão importante no crescimento e desenvolvimento dos seres vivos pluricelulares como também na regeneração de tecidos biológicos.

A incidência de respostas corretas situa-se nos 59,2\%. Embora incluída no grau "Satisfatório" de acordo com a escala qualitativa criada, seria desejável que a percentagem fosse superior, em virtude de se tratar de um conceito fundamental para a compreensão de outros conceitos relacionados com a continuidade da vida e a manutenção das características de cada uma das espécies.

Pretendemos, igualmente, avaliar o conhecimento que os alunos possuíam relativamente à universalidade do código genético, que constitui o património hereditário de cada indivíduo. A descodificação deste código tem sido alvo de múltiplas investigações, que culminaram com a decifração do genoma humano assim como de outras espécies. Os resultados científicos já obtidos são promissores para a resolução de muitos problemas que afetam a humanidade, nomeadamente na área da saúde.

Contudo, somente 18,3\% dos inquiridos responderam corretamente, sendo este resultado "Muito insatisfatório" e não se verificando diferenças entre os dois sexos. 
Sem querermos ser especulativos, ousamos formular algumas possíveis questões que estarão na base destes resultados. Falta de motivação e de gosto dos alunos por esta temática? Insuficiência de tempo para utilização de metodologias diversificadas que permitam a compreensão de código genético, com as suas regras, sinais, descodificação?

Quanto à questão da genética, parece-nos pouco sustentável, dado que a genética se tornou um tema central de debate, designadamente ao nível da clonagem, dos testes genéticos que poderão vir a ser requeridos em locais de trabalho e por seguradoras, da medicina preventiva baseada na investigação em embriões e, mais extensamente, na terapia genética e nos usos dos perfis genéticos de ADN para a constituição de bases de dados para fins forenses. Desde a sequenciação do genoma humano, que estes assuntos se transformaram em temas fulcrais para a construção do futuro da cidadania e da responsabilização do Estado e da sociedade (Costa et al., 2000). A todo este envolvimento da sociedade, a Escola e os alunos não terão sido impermeáveis gerando-se uma dinâmica de discussão catalisadora de interesse e curiosidade da comunidade pelo que a nossa primeira questão formulada parece não ter sustentabilidade.

Os especialistas que elaboram os programas escolares não deveriam ignorar a tensão existente entre o tempo disponível para a lecionação dos conteúdos, por vezes muito extensos, e os objetivos definidos para a aquisição de uma literacia científica satisfatória por parte dos alunos e, simultaneamente, proporcionar uma base sólida de conhecimentos para aqueles que pretendam ingressar no ensino superior.

$\mathrm{Na}$ questão sobre aplicações da engenharia genética nas diversas atividades da sociedade a média de respostas corretas é de 45,3\%. Somente as respostas nos domínios da medicina forense (reconhecimento de cadáveres, identificação de paternidade) tiveram desempenho de grau satisfatório (64,7\%). Porém, o nível de conhecimento relativamente à produção de insulina humana por Escherichia coli é baixo $(31,7 \%)$, registando-se melhor aproveitamento por parte das alunas (35,2\%) enquanto apenas $26,1 \%$ dos rapazes mostram esse conhecimento. Sobre a "produção de alcaloides em quimioterapia por plantas de tomateiro - o valor é baixo (34,8\%) sem distinção entre os rapazes e as raparigas

Os resultados obtidos são surpreendentes na medida em que no Programa do $12 .^{\circ}$ ano de Biologia, o conteúdo conceptual-fundamentos de engenharia genética-, os conteúdos procedimentais e os atitudinais estão claros e objetivos. Além disso, não podemos ainda esquecer o papel desempenhado pelos mass media na divulgação dos avanços da ciência e da tecnologia, embora os alunos considerem, como já atrás analisámos, que a fonte de informação mais relevante na aquisição do conhecimento científico está nas aulas e no saber nelas adquiridas.

Quanto a compreensão dos alunos sobre a transmissão das características hereditárias e tendo por base a construção do Inventário de Conceitos Biológicos, definimos o seguinte conceito principal: Mendel defendeu que cada característica é devida a um par de fatores hereditários presentes nas células do adulto fértil, enquanto que os gâmetas só 
apresentam um desses fatores. Quando ocorre fecundação restabelece-se a existência de pares de fatores hereditários (diploidia). Mendel defendia que o aspeto observável dos indivíduos (fenótipo) era devido a entidades, então misteriosas, a que chamou fatores hereditários (genótipo), que hoje sabemos corresponder aos genes. Através da sua 1. ${ }^{a}$ Lei, Mendel constata que, quando cruza linhas puras com diferentes aspetos de uma característica, obtém uma descendência híbrida, fenotipicamente idêntica à linha pura com a característica dominante, mas genotipicamente diferente. Na 2. ${ }^{a}$ Lei, Mendel defende que os pares de fatores hereditários responsáveis pelas diversas características em estudo num determinado indivíduo segregam-se independentemente uns dos outros aquando da formação dos gâmetas.

As questões formuladas sobre a hereditariedade têm pertinência dado o avanço da genética nas últimas décadas e como ela interfere na vida das pessoas, quer no diagnóstico e determinação do risco de se desenvolverem certas doenças, quer na perspetiva de que algumas delas possam ser curadas pela substituição dos genes defeituosos nas células onde se expressam.

A questão que se refere à $1 .^{a}$ Lei de Mendel, apresenta $65,7 \%$ de respostas certas, isto é, o equivalente a "satisfatório" na escala previamente definida. Embora não sendo um resultado negativo, seria mais ajustado um melhor conhecimento por parte dos inquiridos, mas não foram encontradas discrepâncias entre rapazes e raparigas.

Na questão sobre a atualidade da aplicação das leis de Mendel a muitas características hereditárias. A média ponderada de respostas certas situa-se nos $67,1 \%$, equivalente ao obtido na questão anterior, cujo domínio conceptual abrange a mesma zona do mapa genético. Por outro lado, não encontramos diferenças significativas nas respostas dadas por alunos e alunas.

No nosso entender, no ensino secundário, além da escolha criteriosa das matérias a lecionar, aquando da definição das metodologias, as comissões de especialistas nomeadas pelos decisores políticos deveriam contemplar mais atividades que proporcionem aos alunos revisitar assuntos e rever conceitos prévios que permitam estabelecer pontes entre conhecimentos já adquiridos e outros a adquirir.

$\mathrm{Na}$ questão em que foi solicitado aos inquiridos a interpretação de uma árvore genealógica a partir de dados fornecidos, com o objetivo de avaliar a sua capacidade de aplicação da teoria cromossómica da hereditariedade a uma dada situação. Eles teriam de identificar qual o tipo de hereditariedade em jogo: se era autossómica ou sexual. Por outro lado, os alunos teriam ainda de decidir se cada um desses tipos era dominante ou recessivo. Continua a estar subjacente um conhecimento histórico que se reflete não só na formulação da questão como nas respostas à mesma. Dos inquiridos, apenas 37,8\% foram capazes de interpretar a questão. Estes resultados mostram que uma percentagem elevada não interpretou corretamente a figura referente à árvore genealógica e à localização do gene responsável nos cromossomas somáticos. Ora, a resposta 
a esta questão resultava do conhecimento interligado de vários conceitos numa sequência temporal de modo a serem eliminadas algumas hipóteses e confirmada a correta.

Embora esta matéria seja lecionada a alunos com uma certa maturidade e grau de abstração, as respostas ao questionário não atingiram o patamar da aplicação de conhecimentos a situações concretas, em virtude do não estabelecimento da relação entre as principais ideias da teoria cromossómica da hereditariedade e as imagens interpretativas das mesmas. Apesar de ser um conteúdo procedimental (construção e interpretação de árvores genealógicas), expresso no Programa do $12 .^{\circ}$ ano de Biologia, por razões metodológicas ou limitação de tempo, o aprender fazendo, que prepara os alunos e permite atingir níveis de desenvolvimento cognitivo mais elevados, não foi conseguido e provavelmente não ultrapassou a mera memorização da teoria.

Estes conteúdos não são de desprezar no ensino secundário. Eles realçam o trabalho árduo e persistente dos cientistas na procura de novos resultados que conduzam ao progresso científico. Convém recordar que, com os avanços da genética molecular, aos quais não foram alheios alguns decisores políticos nomeadamente americanos, se conseguiu sequenciar o genoma humano, cuja fase de iniciação teve início em outubro de 1990, com um consórcio governamental com a participação dos Estados Unidos, Inglaterra, França, Alemanha, Japão e China. O trabalho planeado foi concluído antecipadamente, sendo a sua comunicação oficial dada conjuntamente pelo Projeto Genoma Humano e por uma concorrente, a instituição Celera Genomic Corporation.

A questão que se refere à frequência de certas doenças genéticas determinadas por genes recessivos localizados no cromossoma $X$ corresponde a mais um avanço na história da genética, cujo contributo se deve a Thomas Morgan ${ }^{6}$.

A resposta correta pressupõe o conhecimento da constituição dos cariótipos da muIher e do homem no que se refere aos cromossomas sexuais e ao baixo grau de homologia entre os cromossomas $\mathrm{X}$ e Y, cujo conteúdo genético ficou identificado quando da sequenciação do genoma humano.

Foram de $52,1 \%$ as respostas certas, o equivalente ao grau "satisfatório" na escala qualitativa, embora se registassem ligeiras discrepâncias entre alunos $(48,7 \%)$ e alunas (54,3\%).

Atendendo aos conteúdos conceptuais (transmissão de características hereditárias), à valorização dos conhecimentos sobre genética no sentido de desenvolver uma atitude responsável face ao seu papel no melhoramento da qualidade de vida dos indivíduos (conteúdos atitudinais), expressos no Programa da disciplina de Biologia, consideramos que os conhecimentos dos alunos ficam aquém do desejável.

Esta temática, de uma maneira geral, deveria suscitar o interesse dos alunos não só porque permite explicar a continuidade da vida, a transmissão das características de pais para filhos, uma "viagem" à intimidade dos genes permitindo descortinar alguns dos seus "segredos". O penetrar nessa intimidade torna-nos mais atentos às mensagens do corpo 
e aos cuidados que devemos ter na preservação da vida, contribuindo para um equilíbrio biopsicológico de cada um e para a criação de uma sociedade mais ativa, mais autoconfiante e menos dispendiosa em termos de saúde pública.

As questões relacionadas com esta área temática, referentes aos processos reprodutivos dos seres vivos e, mais desenvolvidamente, à reprodução humana, tinham como objetivo poder avaliar o nível de conhecimentos dos alunos.

As questões formuladas fundamentaram-se no seguinte conceito principal: A replicação do ADN fundamenta a existência da divisão celular, estando a mitose na origem da reprodução assexuada. Só é possível a ocorrência de uma reprodução sexuada se, em alguma fase do ciclo de vida dos organismos, houver produção de células por meiose.

$\mathrm{Na}$ questão que se ocupa do ciclo celular, os percentuais de respostas certas, a média ponderada é de 80,6\%, ou seja, equivalente ao grau "bom", embora aproximando-se já da classificação máxima. Não se encontram discrepâncias significativas entre alunos e alunas.

A maioria dos alunos identificou os acontecimentos específicos e comuns à mitose e à meiose, dois processos de divisão nuclear que ocorrem nas células e que são responsáveis pela continuidade da vida, crescimento, desenvolvimento dos indivíduos e biodiversidade. Também associou corretamente cada uma das divisões nucleares aos processos de reprodução assexuada e sexuada. Contudo, no que diz respeito a um dos acontecimentos ocorridos nos dois processos - "a placa equatorial forma-se apenas na mitose, estando ausente na meiose"-as raparigas revelaram maior conhecimento $(86,0 \%)$ do que os seus colegas $(78,6 \%)$.

A ligação do ciclo celular a questões de grande atualidade, como a clonagem e doenças cancerígenas, está hoje na ordem do dia dando um grande avanço científico para a resolução dos problemas com eles relacionados.

Na questão sobre o ciclo biológico humano, a média ponderada de respostas certas é de $67,1 \%$, equivalente ao grau de conhecimento "Bom”. Esta questão compreende cinco itens; nos três primeiros, cujo nível cognitivo se encontra no patamar da memorização, os alunos atingiram valores percentuais elevados (respetivamente 83,2\%, 80,7\% e 74,1\%). Em contrapartida, os outros dois itens pressupõem o domínio dos conceitos implícitos e a sua aplicação às situações propostas, pelo que obtiveram percentagens menos satisfatórias (43,4\% e 54,0\%).

Verificamos, pois, que existe uma grande disparidade no conhecimento evidenciado pelos alunos.

No que se refere à "A reação acrossómica permite ao espermatozoide evitar a polispermia"-, a maioria dos alunos não foi capaz de interpretar aspetos relevantes quanto à fisiologia da reprodução. Comparando o nível de profundidade deste conhecimento com o das outras alíneas direcionadas para saberes mais básicos situados no patamar da memorização, conclui-se que o conceito fundamental da fecundação não foi compreendido. 
Relativamente às alunas, é apenas na alínea referente ao processo de ovulação, que elas se distanciam dos seus colegas (86,0\% e 78,6\% respetivamente) o que se justifica, no nosso entender, pelo facto de se tratar do autoconhecimento do corpo feminino.

Provavelmente uma das causas dos menores conhecimentos evidenciados nestas matérias poderá encontrar explicação nas metodologias utilizadas em sala de aula. Os conteúdos procedimentais sugerem a observação e interpretação de imagens relativas à histologia das gónodas e estrutura dos gâmetas. Sendo esta matéria lecionada no $12{ }^{\circ}$ ano, cuja maturidade dos alunos facilita a discussão sobre a importância do conhecimento da morfo-fisiologia dos órgãos reprodutores e das vantagens que daí advêm na educação sexual, as metodologias a usar devem ser facilitadoras da aquisição dos conceitos e sua aplicação de uma forma segura e confiante. Acresce ainda que o conhecimento aprofundado do corpo, "palco» onde ocorrem os fenómenos da sexualidade, contribui para uma certa desmistificação do tabu que durante muito tempo foi responsável por muitos dos desequilíbrios biopsicológicos, constituindo ainda um precioso alicerce na edificação da educação sexual dos alunos.

Atendendo a que não existe definido um horário específico para o tratamento desta matéria, que tem um caracter pluridisciplinar e transversal, será a disciplina de Biologia um espaço privilegiado para o desenvolvimento de uma das vertentes que constituem a educação sexual. Por outro lado, cabe à Escola o estabelecimento de parcerias com instituições da área da saúde para realização de espaços de debate, pois consideramos que esta temática é uma das muitas faces da educação para a cidadania que a Escola deve promover.

No estudo dos ciclos de vida em que se pretende que os alunos sejam capazes de localizar e identificar os processos de reprodução, não se pode reduzir o ensino- aprendizagem a um somatório de esquemas e nomes sem uma compreensão conceptual do esquema, pensando antes numa gestão de economia de tempo. A abordagem simplista e redutora dos ciclos de vida, no $11 .^{\circ}$ ano, pode ser indutora de uma aprendizagem baseada na memorização e, não, na interpretação e compreensão.

Seguidamente, procuramos avaliar o conhecimento dos alunos sobre o processo de desenvolvimento embrionário de um vertebrado, terminando assim a temática sobre o ciclo celular, a reprodução e o desenvolvimento.

Ainda que fosse elementar o nível de dificuldade da questão, as respostas corretas somente atingiram a média ponderada de 59,7\%, equivalente ao grau "Satisfatório" da escala qualitativa escolhida como referencial de comparação.

Em síntese, face aos resultados, vamos poder afirmar que os inquiridos revelaram uma boa compreensão no que se refere ao processo de continuidade da vida, embora fosse útil que, em algumas temáticas, o grau de proficiência se revelasse superior 
atendendo à importância da formação dos jovens, não só do ponto de vista biológico como também do seu desenvolvimento enquanto cidadãos.

\section{Conclusão}

Neste artigo, pretendemos avaliar o nível de bioliteracia dos alunos que terminavam o ensino secundário, no ano letivo de 2008-2009, e que estudaram segundo as diretrizes programáticas e pedagógicas da reforma da política educativa de 2004 e demais alterações que lhe sucederam.

Perante o avanço acelerado da biologia e os desafios daí decorrentes para a sociedade, predispusemos a investigar em que medida a Escola e, mais concretamente, a disciplina de Biologia contribuem para formar cidadãos cada vez responsáveis e bioliteratos.

O questionário, aplicado a alunos que se encontravam em vias de concluir o ensino secundário, pretende dar um contributo para a avaliação do nível de bioliteracia dos estudantes portugueses no final do ensino secundário, de modo a poder contribuir para uma futura elaboração de propostas de melhorias significativas que possam influenciar os decisores políticos, os especialistas e demais elos da cadeia da Educação. Tais decisões políticas têm a sua máxima expressão na escolha dos currículos, nas abordagens pedagógicas recomendadas, nos manuais escolares adotados, na preparação científica e pedagógica dos professores e demais atores da comunidade escolar, bem como na qualidade das instalações escolares.

Esta cultura de cidadania ambiental deve começar logo no meio familiar e ser consolidada e desenvolvida desde os primeiros anos da Escola para podermos ter cidadãos conscientes, capazes de opinar e intervir neste mundo globalizado, cujo paradigma de desenvolvimento exige, quer por parte dos cidadãos quer dos decisores políticos, em suma, de toda a sociedade, uma política de racionalidade ambiental promotora do desenvolvimento sustentável.

Consideramos que cabe à Escola proporcionar uma vivência efetiva, quer através das metodologias usadas no ensino de alguns conteúdos que possam suscitar uma certa controvérsia (as biotecnologias, o ambiente, a reprodução medicamente assistida, as alterações climáticas, o desenvolvimento sustentável), quer abordando questões éticas decorrentes desse ensino.

\section{Notas}

1 Este artigo teve como base a investigação feita no âmbito do meu Doutoramento em Educação, apresentado e defendido no Instituto de Educação da Faculdade de Ciências Sociais, Educação e Administração da Universidade Lusófona de Humanidades e Tecnologias.

2 A expressão "literacia científica" surgiu pela primeira vez, em 1958, num estudo de Hurd intitulado Science literacy: its meaning for american schools e noutro de Richard MacCurdy (1958), mas pouco se ocuparam quanto a apresentarem um significado preciso. Mais tarde, Pella et al (1966) 
consideraram que a expressão implicava uma compreensão de conceitos básicos de ciência e da sua natureza, assim como os princípios éticos que devem estar presentes num trabalho científico e as relações entre ciência, tecnologia e sociedade.

3 Na questão 26, pedia: "Indique qual a fonte de informação que considera mais relevante na aquisição do conhecimento científico que Ihe permitiu responder ao questionário...".

4 O Protocolo de Quioto, que sucede à Convenção-Quadro das Nações Unidas sobre as alterações climáticas, é um dos instrumentos jurídicos internacionais mais importantes na luta contra essas alterações. Integra os compromissos assumidos pelos países industrializados de reduzirem as suas emissões de determinados gases com efeito de estufa, responsáveis pelo aquecimento planetário.

5 ARNt significa ARN transporte.

6 Embriologista da Universidade da Columbia que realizou estudos aprofundados utilizando como material de investigação a Drosophila melanogaster, também conhecida como mosca do vinagre.

\section{Referências Bibliográficas}

Adão, A. (2001). As políticas educativas nos debates parlamentares. O caso do ensino secundário liceal. Porto: Edições Afrontamento \& Assembleia da República.

Afonso, M. R. (2004). Educação para a cidadania em Portugal. In I. Canhoto \& M.L.S. Mendes (Coords.). Flexibility in curriculum, citizenship and communication (pp. 449-467). Lisboa: Ministério da Educação.

Afonso, N., \& Costa, E. (2009). A influência do Programme for International Student Accessment (PISA) na decisão política em Portugal: o caso das políticas educativas do XVII Governo Constitucional português. Sísifo/Revista de Ciências da Educação, 10, 53-64.

Cruz, L. B. (2008). A biologia, a economia e a energia - Um novo paradigma da ciência económica. Biologia e Sociedade. Revista da Ordem dos Biólogos, 6, 10-11.

EURYDICE (2010). Diferenças de género nos resultados escolares: estudo sobre as medidas tomadas e situação atual da Europa. Lisboa: Comissão Europeia.

Galvão, C. (2003). Educação em ciência: das políticas educativas à implementação do currículo. Atas do $X$ Encontro Nacional de Ensino em Ciências. Lisboa: Universidade de Lisboa.

GAVE (2003), PISA 2000 - Conceitos fundamentais em jogo na avaliação da literacia científica e competências dos alunos portugueses. Lisboa: GAVE

Griffiths, A. (2003). Community-based biology. UNESCO-IUBS Bioliteracy Series n. ${ }^{01}$ International Union of Biological Sciences. Disponível em http://gyanpedia.in/Portals/0/Toys\%20from\%20Trash/ Resources/books/communitybiology.pdf, consultado em 8 de Março de 2016.

Hodson, D. (2008). What is scientific literacy and why do we need it?. In Singh, A. et al. (Orgs.) Multiple perspectives on education and society in Newfoundaland and Labrador. (pp. 4-9). Newdoundaland, Labrador: Memorial University.

Hodson, D. (2011). Looking to the future. Building a curriculum for social activism. Rotterdam: Sense Publishers.

Justino, D. (2010). Difícil é educá-los. Lisboa: Fundação Francisco Manuel dos Santos.

Justino, D. et al. (2004). A reforma do ensino secundário. Porto: Porto Editora. 
Osborne, J., \& Dillon, J. (2008). Science Education in Europe: critical reflexions. A report to the Nuffield Foundation. London: King's College.

Pearson, T. (2009). On the trail of living modified organisms. Environmentalism within and against neoliberal order. Cultural Anthropology, 24 (4), 712-745.

Pella, M. O. et al (1966). Referents to scientific literacy. Journal of Research in Science Teaching, 4 (3), 199-208.

Power, C.N.(1997). Editorial. Connect. UNESCO International Science, Technology \& Environmental Education Newsletter, XXII (1), 3-12.

Programa de Biologia e Geologia, 10. ou 11. anos (2001). Lisboa: ME.

Programa de Biologia e Geologia, $12 .^{\circ}$ ano (2004). Lisboa: ME.

Quintanilha, A. et al. (2003). Cruzamento de saberes, aprendizagens sustentáveis. Lisboa: Fundação Calouste Gulbenkian.

Teodoro, A. (2008). Novos modos de regulação transnacional de políticas educativas. Evidências e possibilidades. In A. Teodoro et al. (Orgs.). Tempos e andamentos nas políticas de Educação: estudos iberoamericanos. (pp. 19-38). Brasília: Liber Livro Editora.

\section{Legislação}

Decreto-Lei n. ${ }^{\circ} 74 / 2004$.

Decreto-Lei n. ${ }^{\circ}$ 07/2001.

Decreto-Lei n. ${ }^{\circ} 7 / 2002$.

Decreto-Lei n. ${ }^{\circ}$ 156/2002.

Decreto-Lei n. ${ }^{\circ}$ 74/2004.

Conceição Soeiro

Licenciada em Bilogia, PhD em Educação

Diretora da COFAC

Email: mcsoeiro@ulusofona.pt

Correspondência

Maria da Conceição Soeiro

Universidade Lusófona

Campo Grande, 3761749-024 Lisboa - Portugal

Data de submissão: Setembro 2016

Data de avaliação: Novembro 2016

Data de publicação: Julho 2017 